\title{
SOBRE A IMPORTÂNCIA DA EDUCAÇÃO EM DIREITOS HUMANOS VOLTADA PARA O ENFRENTAMENTO À VIOLÊNCIA CONTRA A MULHER
}

\author{
Edna Raquel Rodrigues Santos Hogemann ${ }^{1}$ \\ Marilha Boldt ${ }^{2}$
}

\section{Resumo:}

Analisa aspectos relativos à violência contra mulheres, sua relação de causa e efeito com a ambiência cultural que a estimula e legitima, bem como, manifestações no cenário jurídico e legislativo, alguns instrumentos potencialmente eficazes em prevenir e reprimir condutas de violência relacionadas à mulher, mormente no campo educacional. Para o alcance dos fins pretendidos busca sustentação teórica no pensamento de Freire, quanto às propostas educacionais e lastreia-se na concepção de Marshall quanto à cidadania, focada na emancipação do ser humano sob o signo dos Direitos Humanos. Utiliza-se o método de pesquisa exploratório, com recursos bibliográficos e viés dialético.

\section{Palavras-chave:}

Direitos Humanos; violência doméstica; educação; políticas públicas

\section{ON THE IMPORTANCE OF EDUCATION IN HUMAN RIGHTS AIMED AT COMBATING VIOLENCE AGAINST WOMEN}

\begin{abstract}
:
It analyzes aspects related to violence against women, its relation of cause and effect with the cultural environment that stimulates and legitimizes it, as well as, manifestations in legal and legislative scenario, some potentially effective instruments to prevent and repress conducts of violence related to women, especially in educational field. In order to reach the intended goals, study seeks theoretical support in Freire's thought about educational proposals and is based on Marshall's conception of citizenship, focused on emancipation of the human being under the sign of human rights. The exploratory research method is used, with bibliographical resources and dialectic bias.
\end{abstract}

\footnotetext{
${ }^{1}$ Pós-Doutora em Direito, pela Universidade Estácio de Sá/RJ, Doutora em Direito pela Universidade Gama Filho - UGF (2006), Mestre em Direito pela Universidade Gama Filho - UGF (2002), Pós-Graduação Lato Sensu em Bioética, pela Red Bioética UNESCO (2010), Pós-Graduação Lato-Sensu em História do Direito Brasileiro, pela Universidade Estácio de Sá - UNESA (2007), Graduada em Jornalismo, pela Universidade Federal do Rio de Janeiro - UFRJ (1977) e Bacharel em Direito pela Universidade do Grande Rio (1999). Professora Permanente do Programa de Pós-Graduação em Direito e Decana Pro Tempore, da Universidade Federal do Estado do Rio de Janeiro- UniRio. Pesquisadora do GGINNS - Global Comparative Law: Governance, Innovation and Sustainability (Bioethics, Biolaw, Biotecnology) e do Grupo Direito Humanos e Transformação Social . Com endereço Postal situado à Rua Senador Vergueiro, 170/206 Flamengo, RJ, CEP 22230-001, endereço eletrônico ershogemann@gmail.com.

${ }^{2}$ Mestranda em Direito na Universidade Federal do Rio de Janeiro (UNIRIO), Pós-graduação Lato Senso em Processo Civil UCAM (2014), Graduada em Direito pela UNESA (2014). Pesquisadora do Núcleo Interamericano de Direitos Humanos na UFRJ (NIDH/FND), participante do Grupo Direitos Humanos e Transformação Social na UNIRIO, idealizadora do Projeto Superação da Violência Doméstica. Com endereço postal R. Joaquim Távora, no 243, apto 1704, bl 01, Icaraí, Niterói, RJ, CEP: 24230-541. Com endereço eletrônico marilhaboldt2020@gmail.com .
} 


\section{Keywords:}

Human rights; domestic violence; education; public policies

\section{Introdução}

O advento da produção da Lei Maria da Penha (Lei Federal n ${ }^{\circ}$ 11.340/2006) vem provocando uma série de discussões e novas formas de pensar a posição e as relações entabuladas pelas mulheres no seio da sociedade, demarcada pelo signo da reificação de seus membros e pela dinâmica cadenciada pelo direito de propriedade que as transformam em objetos do desejo e posse masculinos.

Tendo em vista que as mulheres são atravessadas por muitas vozes, muitos discursos e muitos jogos de força que devido à existência de um ethos cultural que afirma e perpetua o machismo, é imperioso observar que a Lei Maria da Penha provocou reflexões no que tange ao fato da mulher ser sujeito não somente de deveres, mas também de direitos, através da desconstrução feroz que regem o patriarcado, tornando explícita as formas de violência contra a mulher através das tipificações.

Pode-se refletir o texto da Lei Maria da Penha, como elemento referencial no sentido da punição e sobretudo de prevenção à violência doméstica. Como desdobramento dessa lei diversas políticas públicas foram realizadas no combate à violência, mas a questão é: são eficazes? Infelizmente ainda não se tem respostas satisfatórias.

Pretende-se com o presente ensaio demonstrar que o caminho para a efetividade das normativas que buscam inibir a violência doméstica carecem estar lastreado por uma política pública voltada para a transformação de uma cultura que legitima a violência de gênero. Razão pela qual é no processo educacional voltado para a consagração dos Direitos Humanos que se visl7umbra uma das possíveis saídas para essa questão de profunda gravidade em termos mundiais e em especial, no Brasil.

Para elaborar uma resposta a essa questão tão complexa, busca-se suporte teórico no trabalho elaborado por Paulo Freire no que diz respeito ao processo ensino/aprendizagem voltado para a construção da cidadania libertadora e na concepção de cidadania elaborada na obra de T.S. Marshall, reforçada por algumas abordagens não menos relevantes. Utiliza-se o método de pesquisa exploratório, com recursos bibliográficos e viés dialético. 


\title{
2. Sobre os Direitos Humanos e a proteção à mulher
}

O processo de garantia dos Direitos Humanos no direito internacional se deu através de um processo longo e a sua implementação pelas Cortes Internacionais também como bem pontuado por VAL e LEGALE (2017, p. 03), conforme abaixo:

\begin{abstract}
O processo de garantia por Cortes Internacionais de Direitos Humanos possui um longo processo histórico de implementação, para o qual aprovação da Declaração Universal de Direitos Humanos de 1948 da ONU constitui um importante, mas insuficiente marco a sua compreensão, tendo em vista que apenas nos anos 90 se acelerou a abertura e efetividade da jurisdição internacional (CAPPELLETTI, 2008, PP. 379-397). É verdade que os estudos de caráter cosmopolita que incorporam uma maior normatividade começam na Declaração Universal de Direitos Humanos (1948), passam pelos Pactos de Direitos Civis e Políticos e o Pacto de Direitos Sociais e Econômicos (1966) e continuam nas Declarações e Pactos regionais , como a Declaração Americana de Direitos e Deveres do Homem (1948), conhecida como "Declaração de Bogotá" e a Convenção Americana de Direitos Humanos (1969), conhecida como "Pacto de San José de Costa Rica"
\end{abstract}

A Convenção Americana de Direitos Humanos de 1969 já consagrava alguns direitos básicos, independente do sexo, conforme descrito no seu artigo $1^{\circ}$, além do direito à vida $\left(\operatorname{art.} 4^{\circ}\right)$, direito à integridade pessoal (art. $\left.5^{\circ}\right)$, garantias judiciais (art. 8) e proteção judicial (art. 25).

A primeira Conferência Mundial, organizada pela ONU, sobre a situação jurídica e social da mulher ocorreu em 1975, no México, convocada pela Comission on the Status of Women (CSW), foi de suma importância, pois nela foi trazida para o âmbito internacional a questão de gênero, deixando de ser apenas uma questão de direito interno de cada Estado. O Estatuto da CIM no artigo $2^{\circ}$ dispõe:

\footnotetext{
Artigo 2. A Comissão tem por finalidade promover e proteger os direitos da mulher, bem como apoiar os Estados membros em seus esforços por assegurarlhe pleno acesso aos direitos civis, políticos, econômicos, sociais e culturais, permitindo que mulheres e homens participem em condições de igualdade em todos os âmbitos da vida em sociedade, a fim de que desfrutem total e igualitariamente dos benefícios do desenvolvimento, bem como dividam a responsabilidade do futuro.
}

Com o dever de proteger os direitos e interesses das mulheres, a CIM compreendeu um hiato no texto da Convenção sobre a Eliminação de todas as Formas de Discriminação contra a Mulher (CEDAW), em 1979, no que concerne à inserção da violência contra a mulher no campo jurídico-legislativo, uma vez que não apreciava de 
forma clara e objetiva.

A Declaração Universal dos Direitos Humanos de 1979 teve um marco importantíssimo para as mulheres, pois afirmou que todos os seres humanos nascem livres e iguais em dignidade e direitos.

A Convenção tratou a questão de gênero no campo público e privado, tendo como propósitos básicos refrear quaisquer discriminações contra a mulher e promover os seus direitos na busca da igualdade de gênero. Na área privada, foi assegurada a igualdade entre homens e mulheres nas relações familiares relativos ao casamento, atribuindo a ambos os mesmos direitos e deveres conjugais, diretriz, entretanto, não aceita de plano pelo Brasil. Na área pública, previu a possibilidade de ações afirmativas englobando áreas como trabalho, saúde, educação, direitos civis e políticos (DIAS, 2007).

Nesse contexto, a CIM com a finalidade de elaborar uma ação estratégia multidimensional e multifocal para dar maior efetividade ao combate da violência de gênero, elaborou em 1990, um processo de consulta no âmbito interamericano sobre a situação "mulher e violência", envolvendo também a participação da sociedade civil em nível internacional e as instâncias de decisão da própria OEA.

A consulta objetivou o início de uma investigação e sistematização de propostas para regulamentar de forma mais precisa o fenômeno da violência contra as mulheres nas Américas, com objetivo de extermina-la. Em decorrência desse processo, ficou constatado que havia o predomínio do homem em diversas formas e manifestações de violência contra a mulher, o que levou a CIM preparar um evento, com objetivo de propor atuação própria no campo jurídico-administrativo, bem como de previsão legal e de políticas públicas no combate a estas violências.

Portanto, o Comitê Diretivo da CIM promoveu uma reunião para organizar uma comissão interamericana sobre a mulher e a violência. Resultando no anteprojeto detexto para a Convenção que circulou entre os governos durante o mês de novembro de 1991. A consulta foi ampliada incluindo a Comissão de Parlamentares pertinentes, ministérios, outras agências governamentais, passando por associações profissionais e organizações da sociedade civil (ONGs), organizações de mulheres e de direitos humanos, em cada país da região.

No dia em 9 de junho de 1994, na Vigésimo Quarto Período Ordinário de Sessões da Assembleia Geral, surgiu a Convenção Interamericana para Prevenir, Punir e 
Erradicar a Violência contra a Mulher, também denominada Convenção de Belém do Pará, ratificada pelo Brasil apenas em 27 de novembro de $1995^{1}$, passando o mesmo a vigorar a partir deste momento no âmbito nacional.

A Convenção do Belém do Pará representou um imenso progresso no que concerne ao reconhecimento dos direitos das mulheres e no seu Artigo $1^{\circ}$ da Convenção de Belém do Pará.

Desta forma, os Estados que ratificaram a Convenção assumiram a responsabilidade de garantir as mulheres uma vida livre de violência, em todos os seus aspectos, seja na esfera pública ou nas relações privadas. Destaca-se que a garantia não é apenas de forma passiva de reparação judicial, mas de forma ativa, como bem descrito em seu artigo $7^{\circ}$, onde afirma que os Estados assumiram a obrigação de prevenir que essas agressões ocorram contra as mulheres através de políticas públicas destinados a esse fim, além do descrito no artigo $6^{\circ}, \mathrm{b}$, toda mulher a ser livre de violência observando o direito da mulher a ser valorizada e educada livre de padrões estereotipados de comportamento e costumes sociais e culturais baseados em conceitos de inferioridade ou subordinação.

No mesmo sentido a mesma convenção afirma no Artigo $8^{\circ}$ caput e inciso b que os Estados devem adotar, progressivamente, medidas especificas, inclusive programas destinados modificar os padrões sociais e culturais de conduta de homens e mulheres, igualmente com programas formais e não formais adequados a todos os níveis do processo educacional.

Ou seja, cabe aos Estados que ratificaram a Convenção de Belém do Pará estabelecer políticas públicas que alterem os padrões estereotipados de comportamento e costumes sociais e culturais baseados na subordinação e inferioridade da mulher, em outras palavras, combater o machismo, ideologia segundo a qual o homem domina socialmente a mulher (AURÉLIO, 2015).

O Artigo 12 da Convenção de Belém do Pará, ainda, dispõe sobre os mecanismos internacionais de responsabilização internacional pelo seu descumprimento e reconhecendo a competência da Corte Interamericana de Direitos Humanos.

Caso importante na violação de direitos humanos na questão de gênero foi o caso Cosme Rosa Genoveva e outros x Brasil, na Corte Interamericana de Direitos Humanos (Corte IDH), em que houve 26 homicídios e outros três casos de estupro, sendo duas adolescentes. O fato ocorreu na favela Nova Brasília no Rio de Janeiro. Durante as 
investigações, as mortes foram registradas como "resistência à prisão resultante da morte 
dos opositores" e "tráfico de drogas, grupo armado e resistência seguida de morte". As investigações foram arquivadas em 2009 em decorrência da prescrição dos crimes.

No que diz respeito aos estupros e possíveis atos de tortura a Corte IDH considerou que o Estado violou os direitos às garantias judiciais e à proteção judicial, previstos nos artigos 8.1 e 25 da CADH, em relação ao artigo 1.1 do mesmo instrumento, e os artigos 1, 6 e 8 da Convenção Interamericana para Prevenir e Punir a Tortura, e o artigo 7 da Convenção de Belém do Pará (CBP), em prejuízo das três vítimas.

Com relação às mulheres vítimas de violência sexual, a Corte IDH considerouque, em decorrência da completa falta de investigação, as mesmas experimentaram sentimentos de angústia e insegurança, bem como frustração e sofrimento. A falta de identificação e punição dos responsáveis fez com que a angústia permanecesse por anos, sem que se sentissem protegidas ou reparadas. Resultando na condenação do Brasil em maio de 2017 pela Corte IDH para que o Brasil tomasse várias atitudes de reparação.

Segundo a ONU MULHERES (2011, p. 20) houve uma evolução na América Latina em relação à existência de leis nacionais no combate a violência intrafamiliar como descrito abaixo:

[...] a partir dos anos 1990, vários países da América Latina aprovaram legislação especial para prevenir e erradicar a violência nas relações domésticas e familiares. [...] esta mudança se inicia em 1994, quando Argentina e Chile foram pioneiros na aprovação de leis para coibir a violência familiar e a violência intrafamiliar, respectivamente. Mais tarde, já nos anos 2000 outros países aderiram a este movimento: em 2000, o Paraguai aprovou a Lei Contra a Violência Doméstica, em 2002, o Uruguai aprovou a Lei de Violência Doméstica e, o Brasil, que aprovou, em 2006, a Lei de Violência Doméstica e Familiar contra a Mulher. Em 2005, o Chile aprovou a Lei 20.666 sobre Violência Intrafamiliar, que substituiu a lei de 1994.

O Brasil, somente 12 anos depois da assinatura da Convenção de Belém do Pará, criou a Lei 11.334/2006, após as Recomendações da Comissão Interamericana de Direitos Humanos no caso Maria da Penha x Brasil.

Ressalta-se que embora no Brasil, antes de 2006 não havia Lei específica sobre a temática, havia na Constituição de 1988 alguns direitos já reconhecidos como o Artigo 226, § $8^{\circ}$ em 1988 já afirmava que cabe ao Estado assegurar a "assistência à família na pessoa de cada um dos que a integram, criando mecanismos para coibir a violência no âmbito de suas relações". 
Vale dizer que a mesma Constituição garantiu, ainda, que o Estado assegurará mecanismos para coibir a violência nas relações familiares, conferindo a todos os cidadãos igualdade independente de sexo trata-se de uma máxima como a dignidade da pessoa humana, como falar em igualdade e dignidade da pessoa humana sem falar em uma vida livre de violência doméstica?

A violência doméstica pode ser considerada como uma funcionalização do ser humano mulher, pois é tida dentro de um relacionamento abusivo como objeto de prazer, sofrendo diversas formas de tortura por parte do agressor.

A violência doméstica pode ser considerada como uma funcionalização do ser humano mulher, pois é tida dentro de um relacionamento abusivo como objeto de prazer, sofrendo diversas formas de tortura por parte do agressor.

Verifica-se que o princípio da dignidade da pessoa humana está intrínseco com o direito a igualdade, pois não há que se falar em dignidade da pessoa humana havendo desigualdades, desta forma observa-se que quando as mulheres sofrem com agressões, apenas por serem mulheres há uma desigualdade gerada pela violência sofridapor estas.

Os Direitos Humanos segundo, BOBBIO (1992, p.17-30), tratam de princípios universais: o respeito à vida, à liberdade, à igualdade e a dignidade, sem o queinexiste segurança do pleno desenvolvimento da personalidade humana. São aqueles direitos cujo reconhecimento é condição necessária para o aperfeiçoamento da pessoa humana e para o desenvolvimento da civilização.

A Lei Maria da Penha no seu Artigo 8, inciso V que para o combate à violência se faz necessário atividades em conjunto com diversos organismos afim de promover campanhas educativas de prevenção à violência doméstica e familiar contra a mulher, voltadas ao público escolar, ou seja, a própria lei já determina que seja ensinada o seu conteúdo nas escolas.

Além da própria Convenção de Belém do Pará a própria Lei Maria da Penha ressalta a importância em promoções de campanhas educativas a título de políticas de prevenção da violência doméstica no âmbito escolar.

A situação é tão importante que, no Estado do Rio de Janeiro há inclusive um Decreto Estadual $n^{\circ} 7.477 / 2016$ que trata especificamente do ensino da Lei Maria da Penha no âmbito do Ensino Médio.

O projeto Sementes da Paz implementado no município do Rio de Janeiro tem 
desenvolvido pelo Departamento de Ações Pró-Sustentabilidade do Tribunal de Justiça do Estado do Rio de Janeiro (DEAPE), é voltado para os professores da rede estadual de ensino, capacitando-os para lidar com crianças e adolescentes envolvidos direta ou indiretamente em casos de violência doméstica e familiar. Para isso, são promovidas palestras e grupos de reflexão.

A educação entrou no rol dos direitos sociais, no séc. XX, passando a integrara cidadania no rol comum cidadania como denominador comum entre os mais diversos movimentos políticos contemporâneos (mulheres, negros e minorias étnicas, homossexuais, idosos e pensionistas, consumidores, ecologistas, trabalhadores urbanos e rurais) e setores ligados a questões urbanas das grandes cidades como moradia, saúde, educação, desemprego, violência.

O estudo da cidadania não é algo inédito e muitos cientistas sociais o tem abordado sob diferentes perspetivas. De forma geral, é categórico apontar como uma referência comum o texto de T.H. Marshall, Cidadania, classe social e status. Nesse estudo, o sociólogo está interessado em verificar a possibilidade de todos os indivíduos virem a ser considerados como cidadãos, como detentores de direitos universalmente reconhecidos pelo Estado e pelos outros indivíduos. Assim, ele parte sua análise da noção de cidadania como um status: "Cidadania é um status concedido àqueles que são membros integrais de uma comunidade." e aborda "o impacto de uma noção em rápido desenvolvimento, e dos direitos da cidadania sobre a estrutura de desigualdade social." (MARSHALL, 1967, p. 34)

O autor postula que "há uma espécie de igualdade básica associada com o conceito de participação integral na comunidade _ ou, como diria eu, de cidadania _ o qual não é inconsistente com as desigualdades que diferenciam os vários níveis econômicos na sociedade." Ou seja, e é paradoxal, mas "a desigualdade de classes sociais pode ser aceitável desde que a igualdade de cidadania seja reconhecida", acredita MARSHALL (1967, p.36).

A noção de cidadania abordada, parte do pressuposto da nova realidade criada pelas modificações impostas às relações sociais e políticas após um século de lutas operárias e populares, com a irrupção e extensão do movimento operário internacional durante o século XX e, em particular, a vitória contra o nazi-fascismo e as conquistas sociais que daí se seguiram. Percebe-se um esforço por adequar formulações anteriores 
sobre os direitos políticos e sociais à situação do capitalismo britânico do pós-guerra, como uma adaptação da concepção da cidadania burguesa clássica aos tempos do pósguerra e do Welfare State.

Algumas das ideias de Marshall tiveram grande influência posterior naretomada da formulação de cidadania e para tentar compreender a evolução social a partir dela. Para isso, tratou de fazer um histórico do desenvolvimento da cidadania moderna, dividindo-a em três partes: a civil (direitos individuais básicos), a política (participação no poder político) e a social (bem-estar econômico e segurança).

BARCELLONA (1996, p. 36), em seu texto A Estratégia Improvável da Cidadania, demonstra que o centro da noção de cidadania em Marshall é atribuir a essa categoria umnovo significado - de acesso dos membros da comunidade a direitos sociais básicos que permitam integrar os setores mais pobres à sociedade, dar-lhes um sentido de inclusão, à medida que no próprio status de cidadão estejam incorporados determinados direitos sociais e isso possa diminuir a desigualdade social.

Entende-se, portanto, como o exercício da cidadania nova ou cidadaniaampliada com o conceito do exercício da educação que foi formulada pelos movimentos sociais que, a partir do final dos anos setenta e ao longo dos anos oitenta, se organizaram no Brasil em torno de demandas de acesso aos equipamentos urbanos, é fundamental no caminho da inclusão social.

\section{Em questão as políticas públicas nacionais de enfrentamento à violência contra a mulher}

É certo que as políticas públicas dependem de previsão orçamentária, sem a qual sua execução fica prejudicada, especialmente no cumprimento do direito social como aplicação de direitos humanos. $\mathrm{O}$ direito potestativo influencia diretamente na previsão orçamentária através do plano plurianual (PPA), da lei de diretrizes orçamentárias (LDO) e da lei orçamentária (LOA).

Contudo diante das dificuldades financeiras, especialmente no Estado do Rio de Janeiro e no Município do Rio de Janeiro, o processo de elaboração das políticas públicas fica deveras comprometido. Ademais, segundo Bucci (2013, p. 25):

Diante das dificuldades da implantação de um processo centralizado de planejamento, em face da debilidade e descoordenação dos instrumentos de 
ação do Estado brasileiro, a formulação e implementação das políticas públicas se explica como forma de ação que viabiliza o planejamento como atividade de baixa institucionalidade, referida a setores específicos, dependente da capacidade de articulação do Estado localizada e em períodos determinados. As políticas públicas resultam de ação coordenada pelo Estado, mas de forma limitada, o que, paradoxalmente, viabiliza algum grau de planejamento, ainda que de forma particularizada sobre cada programa ou conjunto de programas de ação."

Ou seja, a prática das políticas públicas acaba por depender das articulações políticas entabuladas numa sociedade de cariz patriarcal para a sua concretude, tendo em vista o deficit da viabilidade de planejamento dos projetos de políticas públicas e por isso planejar e estruturar uma boa política pública é de suma importância. DYE (2014, p.109) ressaltaem sua obra Mapeamento dos Modelos de Análise de Políticas Públicas que:

\begin{abstract}
É importante lembrar que o impacto dos arranjos institucionais nas políticas públicas é um problema empírico que merece investigação. Muito frequentemente reformadores entusiastas têm afirmado que uma mudança específica na estrutura institucional provocaria mudanças nas políticas públicas, sem que, porém, tenham estudado a verdadeira relação que existe entre a estrutura e as políticas. Caíram na armadilha de supor que as mudanças institucionais provocariam mudanças políticas. Devemos ser cautelosos em nossa avaliação do impacto da estrutura sobre as políticas. Talvez descubramos que tanto a estrutura quanto as políticas são em grande parte determinadas por forças econômicas ou sociais e os diferentes arranjos institucionais terão pouco impacto independente sobre as políticas, se as forças políticas permanecerem constantes.
\end{abstract}

Dessa forma para se alcançar uma política pública efetiva é necessário assegurar a constância econômica e social para que produza resultados efetivos para o povo.

Mesmo com tantos desdobramentos no Estado do Rio de Janeiro tem-se diversas iniciativas de políticas públicas para as mulheres em situação de violência doméstica, como a patrulha Maria da Penha, projeto implementado pela Polícia Militar do Estado do Rio de Janeiro que visa fiscalizar o cumprimento das medidas protetivas ${ }^{2}$. Um projeto semelhante a este foi lançado no ano de 2020, intitulado Ronda Maria da Penha no município do Rio de Janeiro, composto pela Guarda Municipal em parceria com o Conselho de Direitos das Mulheres com objetivo de fortalecer a rede de proteção à mulher.

No âmbito do Poder Judiciário, o Tribunal de Justiça do Estado do Rio de Janeiro, através de diversas iniciativas para o combate à violência, tem se destacado com iniciativas como o Observatório Judicial de Violência contra a Mulher, que corresponde a um banco de dados disponibilizado no sistema do Poder Judiciário do Estado do Rio de 
Janeiro, trazendo um compilado de informações valiosas a respeito das várias vertentes da violência doméstica e de gênero.

Tem-se, ainda, o Projeto Violeta, com objetivo integrar os diferentes tipos de atendimentos, acelerando o acesso à Justiça àquelas que estão com sua integridade física e sua vida em risco. Todo o processo deve ser concluído em até 4 horas: a vítima registra

\footnotetext{
${ }^{2}$ Tendo em vista o período de pandemia da COVID-19 que se vivencia, o aumento do índice de ocorrências relacionadas à violência doméstica percebe-se, ainda mais. a necessidade de discorrer sobre este fato sóciojurídico.
}

o caso na delegacia, que o encaminha diretamente ao juiz. Após ser ouvida e orientada por uma equipe multidisciplinar do Juizado, a vítima sai com uma decisão judicial em mãos ou, ainda, poderá ser encaminhada aos abrigos especializados.

Nesse mesmo sentido existe o Protocolo "Violeta Laranja" que deu a mesma celeridade entre o registro do fato e a decisão judicial que concede medidas protetivas, bem como dar maior efetividade e proteção às vítimas sobreviventes e indiretas nos processos de feminicídio.

Ainda no âmbito do Tribunal de Justiça do Estado do Rio de Janeiro foi criada a Coordenadoria Estadual da Mulher em Situação de Violência Doméstica e Familiar (COEM), órgão permanente ao Poder Judiciário que visa através de reuniões periódicas com a rede de atendimento à mulher buscar maiores soluções às vítimas.

No mesmo sentido, dentro do Tribunal de Justiça a Central Judiciária de Abrigamento Provisório da Mulher Vítima de Violência Doméstica - CEJUVIDA, é o órgão responsável por fazer o encaminhamento das mulheres vítimas de agressões e de seus filhos menores de idade às chamadas Casas-Abrigo - estas últimas destinadas a conferirem proteção e segurança a essas vítimas, com atendimento psicossocial, jurídico e direcionamento a programas de geração de renda, incluindo acompanhamento pedagógico às crianças e adolescentes.

Outra iniciativa muito importante durante a pandemia foi o Maria da Penha Virtual, parceria entre a Universidade Federal do Rio de Janeiro e o Tribunal de Justiça do Rio de Janeiro, disponível por enquanto para a Capital do Estado do Rio de Janeiro que viabilizou um web app onde através de um link a vítima pode preenchendo o formulário e ao final gera uma petição inicial que vai diretamente para o e-mail do juiz competente, que análise o pedido da medida protetiva que já se torna o processo virtual. 
Dentro do Instituto Médico Legal (IML) tem-se a sala lilás, presente em diversas unidades do estado do Rio de Janeiro, um espaço criado para prestar atendimento especializado e humanizado às mulheres vítimas de violência física e sexual.

No âmbito da Defensoria Pública do Estado do Rio de Janeiro existe o NUDEM Núcleo Especial de Defesa dos Direitos da Mulher e de Vítimas de Violência de Gênero, com uma equipe multidisciplinar que engloba o atendimento jurídico - com as defensoras públicas - e o psicossocial - com a psicóloga e a assistente social.

$\mathrm{Na}$ maioria dos municípios do estado do Rio de Janeiro existem Centros Especializados de Atendimento à Mulher, municipais e estaduais que visam no atendimento psicossocial das mulheres a orientação jurídica para as vítimas.

Outra inovação importante durante a pandemia foi o telefone 197 novo meio de contato entre vítima e a Polícia Civil, através das Delegacias Especializadas de Atendimento à Mulher (DEAMS), onde a mesma pode fazer o Registro de Ocorrência por telefone, este funciona em horário comercial, durante a semana.

Essas iniciativas buscam combater à violência doméstica, contudo todos os dias é noticiado que mulheres são agredidas, e vivenciam o feminicídio.

Mesmo com diversas políticas públicas no enfrentamento à violência doméstica, segundo o Instituto de Segurança Pública do RJ, no Dossiê Mulher 2020, referente ao ano de 2019 constatou-se que a cada 05 horas foi registrado uma ocorrência por lesão corporal dolosa, a cada 10 vítimas de estupro, sete têm até 17 anos. Constatou-se que houveram 26 casos por mês de homicídios dolosos contra as mulheres em 2019, foram 708 tentativas de homicídios contra as mulheres em 2019 no estado do RJ.

Observa-se que para que se possa romper com os casos da violência doméstica a ONU projetou 17 Objetivos de Desenvolvimento para um Mundo Sustentável visando acabar com a pobreza, proteger o meio ambiente, o clima e garantir que as pessoas, em todos os lugares, possam desfrutar de paz e de prosperidade.

Na Agenda para 2030 do Brasil, seguindo as 17 ODS é importante destacar as ODS n' 4 - "Educação de Qualidade em que assegura uma a educação inclusiva e equitativa e de qualidade, e promover oportunidades de aprendizagem ao longo da vida

para todos" em suas Metas “4.5”, “4.7” e "4c" classificando a educação como um desenvolvimento sustentável afim de alcançar a paridade de gênero e igualdade de gênero. 
Já a ODS 5 que busca a igualdade de gênero reafirma o compromisso dos estados partes de alcançar a sustentabilidade global através das Metas "5.2", "5.3" e "5.6”, ou seja, findar com toda e qualquer forma de violência contra a mulher.

Da mesma forma a ODS 16 que busca Paz, Justiça e Instituições Eficazes em sua meta "16.a" busca fortalecer as instituições nacionais relevantes, inclusive por meio da cooperação internacional, para a construção de capacidades em todos os níveis, em particular nos países em desenvolvimento, para a prevenção da violência e o combate ao terrorismo e ao crime.

Observa-se que para alcançar um mundo sustentável precisa-se buscar o fim da violência contra a mulher, não existindo igualdade de gênero quando há violência. Obedecendo essa racio nada melhor do que utilizar a educação como forma de prevenção à violência contra a mulher.

Todas as iniciativas acima citadas são de extrema relevância, contudo ainda não se vê uma solução efetiva para a prevenção e nesse sentido para a efetividade da educação da Lei Maria da Penha.

\title{
4. Educação como alicerce estratégico no enfrentamento à violência de gênero
}

As cifras relativas aos casos de violência contra a mulher, em especial a violência doméstica estão a demonstrar que na sociedade como um todo e em especial, na sociedade brasileira existe uma naturalização do machismo, que muitas das vezes evolui e se materializa por meio das mais distintas formas de violência, seja ela de cunho psicológico, das lesões corporais e, desafortunadamente o feminicídio, o que coloca nosso país na triste posição de quinto país, em nível mundial, pelo número de mortes violentas de mulheres.

\begin{abstract}
Muito da violência doméstica está aliada à perspectiva de que o homem é dono da sua mulher, filha, da entenda, da sobrinha, daquela menina que tá no ponto de ônibus, na escola (...) Há que se ter educação de gênero e isso começa na escola e passa para a família, para que as meninas sejam consideradas sujeitos de direito e não coisas. (FRISCHEISEN, 2018, p. 1)
\end{abstract}

Piovesan e Pimentel observam a educação como uma forma eficaz no combate à violência doméstica, segundo toda a legislação existente, como descrita abaixo: 
consagra medidas integradas de prevenção, por meio de um conjunto articulado de ações da União, Estados, Distrito Federal, Municípios e de ações não-governamentais. Sob o prisma multidisciplinar, determina a integração do Poder Judiciário, Ministério Público, Defensoria Pública, com as áreas da segurança pública, assistência social, saúde, educação, trabalho e habitação. (PIOVESAN e PIMENTEL, 2011, p.113-114)

Realçada se revela a importância da promoção e realização de campanhas educativas de prevenção da violência doméstica e familiar contra a mulher, bem como da difusão da Lei e dos instrumentos de proteção dos direitos humanos das mulheres. Acresce a importância de inserção nos currículos escolares de todos os níveis de ensino para os conteúdos relativos a direitos humanos, à equidade de gênero e de raça, etnia e ao problema da violência doméstica e familiar contra a mulher ${ }^{3}$.

\footnotetext{
${ }^{3}$ Por isso, o Ministério da Educação (MEC) estaria desenvolvendo uma plataforma para a educação básica que trata de direitos humanos e igualdade, incluindo igualdade de gênero. A plataforma vai funcionar como um espaço aberto de conteúdo digital destinado a qualquer cidadão. Mas, segundo Patrícia, a fala é
}

Para concretizar a educação contra a violência doméstica é necessário que haja uma pedagogia adequada para que todos possam não apenas compreender, mas internalizar provando uma mudança cultural, deixando de ser dominado pela cultura machista, mas passando a libertar-se desses paradigmas como Paulo Freire propõe ao afirmar em sua obra Pedagogia do Oprimido que "Quando a educação não é libertadora, o sonho do oprimido é ser o opressor." (FREIRE, 1997, p. 23)

Nessa obra que é a mais citada do autor, estudada e colocada em prática mundialmente e, a apontar-se, também sua obra mais questionada pelo pensamento neoliberal e conservador, Freire promove intensa reflexão em como a educação escolar, de maneira especial a escola pública, organiza-se e materializa a implementação de políticas comprometidas com a reprodução e perpetuação dos processos de dominação e em que medida uma pedagogia e uma metodologia de ensino podem estar a serviço da manutenção de valores sociais existentes que confirmam e conferem legitimidade aos processos de dominação de classe, de opressão das minorias; no que se pode aí consideram também a opressão de gênero ${ }^{4}$. Sem uma educação que seja didaticamente libertadora, o ser humano ao ser oprimido, não tem a consciência em si e para si dessa opressão que é, então, naturalizada e tende a não considerar ser necessário o fim do sistema que lhe oprime, mas sim o caminho de tornar-se também parte da opressão, reproduzindo os valores que lhe são inculcados através do processo de 
ensino/aprendizagem.

Razão pela qual, com especial propriedade, Freire adverte no sentido de que "A educação é um ato de amor, por isso, um ato de coragem. Não pode temer o debate. A análise da realidade. Não pode fugir à discussão criadora, sob pena de ser uma farsa." (FREIRE, 1997, 123).

A realidade objetiva está a demonstrar que de nada adianta a existência de leis severas em relação às práticas de violência contra as mulheres, se não se consegue mudar a cultura nacional que legitima essas práticas. Necessário, pois, uma prática

direcionada à comunidade escolar e às famílias, com texto leve, de fácil compreensão, mas sem ser superficial. Ela será composta por módulos formativos. Um deles vai tratar sobre diversidade na escola e questões de preconceito, discriminação e bullying; outro sobre o que é educação e direitos humanos, como aparece no cotidiano; e um terceiro sobre mediação de conflitos, como eles são importantes para levantar questões e como podem ser encaminhados na escola. Disponível em: https://agenciabrasil.ebc.com.br/politica/noticia/2018-09/educacao-de-genero-na-escola-previnefeminicidios-dizem-especialistas

${ }^{4}$ Na obra, Freire denuncia, de modo claro, que há, em nosso país, uma educação para uns diferentes de uma educação que é oferecida para outros, reflexo de uma sociedade de classes, caracterizada por uma elite opressora e um contingente volumoso de oprimidos.

educacional que comece desde a tenra infância das crianças no sentido do conhecimentoe do respeito aos Direitos Humanos como um todo, e, em especial, tendo em conta o objeto do presente ensaio, uma educação voltada à transformação desse ethos patriarcale machista.

Razão pela qual pugna-se por uma educação em Direitos Humanos voltada para o criar de uma cultura cujo centro seja o ser humano em si, independente se homemou mulher, naturais titulares de direitos e deveres lastreados pelo sobreprincípio da dignidade da pessoa humana.

Para tal, necessário se faz iniciar pelo básico. Há que se promover um processo de alfabetização voltado para o respeito e ao sentimento de solidariedade como bastiões infraestruturais, imprescindíveis à salutar convivência construtiva. De modo querespeito aos Direitos Humanos seja estimulado e se naturalize como elemento estrutural do interior do indivíduo e se converta em modo de vida.

De todo modo, há que se admitir a existência de diversas iniciativas nesse sentido, mormente no que diz respeito ao combate ao machismo e a proteção das mulheres no seio de nossa sociedade. Vários são os dispositivos legais existentes e as iniciativas legislativas em curso.

Ressalte-se a existência de Lei Municipal no Rio de Janeiro que também obriga 
na educação da Lei Maria da Penha nas escolas municipais conforme Lei 6.427/2018.

No Piauí tem-se o projeto Lei Maria da Penha nas Escolas: Desconstruindo a Violência e Construindo o Diálogo. Trata-se de mais um projeto no âmbito educacional, dessa vez voltado ao ensino infantojuvenil. Em parceria com a Secretaria de Estado da Educação (SEDUC) e com o Ministério Público do Estado do Piauí, tem como objetivo difundir o conhecimento acerca da Lei 11.340/2006 nas escolas estaduais, mediante promoção de palestras aos alunos e de cursos de capacitação para professores, além de outras atividades interativas e multidisciplinares.

Iniciado em 2013, após três anos, a iniciativa passou a contar também com a cooperação do NUPEVID. Ganhador do Prêmio Innovare de 2016, a "Lei Maria da Penha nas Escolas" passou a ser difundida também entre as escolas municipais do Piauí. Segundo os autores do projeto, desde o ano de sua execução, ele tem gerado resultados profícuos para as instituições de ensino, sobretudo para seus estudantes. Na edição do ENEM de 2015, o tema da redação foi sobre violência doméstica e familiar contra a mulher, o que possibilitou um alto índice de aprovações nesse vestibular por parte dos candidatos desse Estado.

Essa é mais uma política pública que cumpre o caráter preventivo e educativo da Lei Maria da Penha, disposto em seu artigo $8^{\circ}$, além de concretizar as recomendações feitas pela Comissão Interamericana de Direitos Humanos - CIDH ao Brasil para prevenir e coibir atos de tolerância estatal frente à violência doméstica. Dentre elas, presente no Relatório $\mathrm{n}^{\mathrm{o}} 54 / 0145$, está justamente a de “incluir em seus planos pedagógicos unidadescurriculares destinadas à compreensão da importância do respeito à mulher e a seus direitos reconhecidos na Convenção Belém do Pará”.

\section{Considerações finais}

Caminha-se para a finalização do presente ensaio, tendo por pressuposto objetivo considerado ao longo do presente texto que os Direitos Humanos só podem ser considerados como tal, caso estejam assegurados por deveres correlatos estruturalmente institucionalizados. O livre exercício das capacidades substantivas é fator que ocupa a posição de instrumento e objetivo, em paralelo.

Vislumbrou-se também que a violência contra a mulher é um problema social,de 
caráter público, historicamente enraizado na cultura da humanidade; relacionado a essa concepção, em que pese o Brasil ter implementado políticas públicas, promulgado leis que atendam aos parâmetros internacionais, de valorização, de combate à violência e de empoderamento da mulher, ainda, se constitui um óbice, a própria cultura arraigada, advinda de uma época em que a mulher, a criança, os idosos, eram objetificados.

O patriarcalismo existente no Brasil, fez com que, por séculos, e ainda nos dias atuais, a mulher fosse posta em situação de risco devido aos conceitos machistas e opressores que eram disseminados socialmente. Contudo, como a evolução do Direito, tende a acompanhar a evolução, humana e tecnológica, as regras jurídicas e os meios utilizados para o combate e a prevenção da violência doméstica, têm se mostrado mais ostensivo, a exemplo do Projeto de Lei no 2.510/2020, que versa sobre a obrigação de denúncia, por síndicos e/ou moradores, em caso de ocorrência de violência doméstica.

Com isso, percebe-se a necessidade e a importância de promover o debate e a conscientização dentro das escolas a respeito da violência doméstica contra a mulher e de gênero. O público jovem, em fase de crescimento e de amadurecimento, conseguirá, assim, desenvolver práticas que coadunem com as normas constitucionais, tais como o respeito pela dignidade humana e a promoção da igualdade material. A prática dessas atividades nas escolas e nas universidades vem caminhando a passos largos em determinadas localidades do país, apesar de ainda existirem obstáculos burocráticos e políticos em sua implementação.

\section{Referências}

ALERJ. Decreto Estadual no 7477. Dispõe Sobre O Ensino De Noções Básicas Da Lei Maria Da Penha, No Âmbito Das Escolas Estaduais Do Estado Do Rio De Janeiro, 2016. Disponível em: <http://www2.alerj.rj.gov.br/lotus_notes/default.asp?id=53\&url=L2NvbnRsZWkubnN mL2M4YWEwOTAwMDI1ZmV1ZjYwMzI1NjRIYzAwNjBkZmZmL2VkOWQ2YTQ xODU0MTNiNDI4MzI1ODA1ZTAwNThmZWQ1P09wZW5Eb2N1bWVudA==>.

Acesso em: 01 dezembro 2020.

BANDEIRA, Lourdes Maria; ALMEIDA, Tânia Mara Campos de. Vinte anos da Convenção de Belém do Pará e a Lei Maria da Penha, 2015. Disponível em: 
<http://www.scielo.br/scielo.php?pid=S0104-

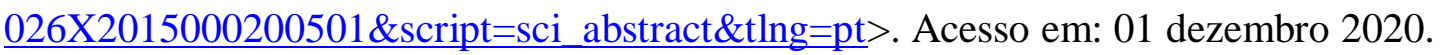

BARCELLONA, Pietro. O Egoísmo Maduro e a Insensatez do capital. São Paulo: Ícone Editorial, 1996.

BOBBIO, Noberto. A Era dos Direitos. Tradução: Carlos Nelson Coutinho. $4^{\circ}$ ed. Rio de Janeiro: 1992. P.17-30.

BUCCI, Maria Paula Dallari. Fundamentos para uma teoria jurídica das políticas públicas. São Paulo: Saraiva, 2013, p. 25-108.

COMISSÃO INTERAMERICANA DE DIREITOS HUMANOS. Caso 12.051 Maria Da Penha Maia Fernandes Brasil. Disponível em: < https://www.cidh.oas.org/annualrep/2000port/12051.htm> Acesso em: 15 dez. 2020. CONSELHO ESTADUAL DOS DIREITOS DAS MULHERES. Centros Especializados de Atendimento a mulher em situação de violência. Disponível em: http://www.tjri.jus.br/documents/10136/5367968/ceam.pdf. Acesso em: 01 dezembro 2020.

CONVENÇÃO AMERICANA DE DIREITOS HUMANOS (1969). Original disponível em: 〈https://www.cidh.oas.org/basicos/portugues/c.convencao americana.htm>. Acesso em 01 dezembro 2020.

CORTE INTERAMERICANA DE DIREITOS HUMANOS. Caso Favela Nova Brasília Vs. Brasil Disponível em:<http://www.corteidh.or.cr/docs/casos/articulos/seriec_333_por.pdf>. Acesso em: 02 outubro 2020.

Def, 12. Dicionário AURÉLIO de Língua Portuguesa, 2015. Disponível em: <https://dicionariodoaurelio.com/machismo $>$. Acesso em 23 de agosto de 2020. DEFENSORIA PÚBLICA DO ESTADO DO RIO DE JANEIRO. NUDEM. Disponível em: https://defensoria.rj.def.br/noticia/detalhes/5351-Nucleo-de-defesa-da-mulhercontra-a-violencia-completa-vinte-anos . Acesso em 30 de dez de 2020.

DIAS, Maria Berenice. A Lei Maria da Penha na justiça. São Paulo: RT, 2007.

DYE, Thomas. Mapeamento dos Modelos de Análise de Políticas Públicas. In: HEIDEMANN, Francisco G.; SALM, José Francisco. Políticas Públicas e Desenvolvimento. Brasília: UNB, 2014. p. 109-142.

FREIRE, Paulo. Pedagogia do Oprimido. 23 ed. São Paulo: Paz e Terra, 1994, p.47-48.

FRISCHEISEN, Educação de gênero na escola previne feminicídios, dizem especialistas, 
in Agência Brasil, 2018. Disponível em:

https://agenciabrasil.ebc.com.br/politica/noticia/2018-09/educacao-de-genero-na-escolaprevine-feminicidios-dizem-especialistas. Acesso em 01 fev 2021.

INSTITUTO INNOVARE. A lei Maria da Penha nas escolas: desconstruindo a violência, construindo diálogos. Disponível em: < https://www.premioinnovare.com.br/praticas/5129> Acesso em: 02 jan. 2021.

MARSHALL, T. H. Cidadania, Classe Social e Status. Rio de Janeiro: Zahar Editores, 1967.

MUNICÍPIO DO RIO DE JANEIRO. Ronda Maria da Penha. Disponível em https://prefeitura.rio/cidade/guarda-municipal-capacita-41-agentes-para-integrar-a-ronda-maria-da-penha/ Acesso em: 04 jan. 2021.

NAÇÕES UNIDAS DO BRASIL. Os Objetivos de Desenvolvimento Sustentável no Brasil. Disponível em: https://brasil.un.org/ >. Acesso em: 31 dez. 2020

PIOVESAN, Flavia. PIMENTEL, Silvia. A Lei Maria da Penha na perspectiva da responsabilidade internacional do Brasil. In: CAMPOS, Carmen Hein de (org). Lei Maria da Penha: comentada em uma perspectiva jurídico-feminista. Rio de Janeiro: Lumen Juris, 2011, p.113-114.

REDE. Estatuto da Comissão Interamericana de Mulheres, 1928. Disponível em: <https://www.oas.org/XXXIVGA/portug/reference docs/Estatuto CIM.pdf>. Acesso em 23 de agosto de 2020.

REDE Brasil de Direitos Humanos. Declaração Universal de Direitos Humanos, 1948. Disponível em: <http://www.dhnet.org.br/direitos/deconu/textos/integra.htm>. Acesso em: 25 agosto 2020.

REDE Brasil de Direitos Humanos. Convenção sobre a Eliminação de todas as Formas de Discriminação contra a Mulher, 1979. Disponível em:

<http://www.dhnet.org.br/direitos/sip/onu/mulher/lex121.htm>. Acesso em: 08 agosto 2020.

VAL, Eduardo Manuel. LEGALE, Siddharta. Direitos Humanos, Direito Internacional E Direito Constitucional: Judicialização, Processo E Sistemas De Proteção I, 2017. Disponível em: <https://www.conpedi.org.br/publicacoes/c7yrg601/lcnv2140/Nm4OSIV1Hkq28X37.p df. Acesso em: 19 setembro 2020. 
TRIBUNAL DE JUSTIÇA DO ESTADO DO RIO DE JANEIRO. Patrulha Maria da Penha. Disponível em:http://www.rj.gov.br/NoticiaDetalhe.aspx?id_noticia=720 Acesso em: 19 setembro 2020.

TRIBUNAL DE JUSTIÇA DO ESTADO DO RIO DE JANEIRO. $1^{\circ}$ Relatório de Dados Compilados sobre Violência Doméstica e Familiar. Observatório Judicial de Violência contra a Mulher. Rio de Janeiro, 2016. Disponível em: http://www.tjrj.jus.br/documents/10136/3480102/01-relatorio-dados-compiladosobservatorio.pdf Acesso em: 30 dez. 2020.

TRIBUNAL DE JUSTIÇA DO ESTADO DO RIO DE JANEIRO. Projeto Violeta. Disponível em: $\quad$ http://www.tjrj.jus.br/noticias/noticia/-/visualizarconteudo/5111210/6259968. Acesso em: 30 dez. 2020.

TRIBUNAL DE JUSTIÇA DO ESTADO DO RIO DE JANEIRO. Protocolo Violeta Laranja. Disponível em http://www.tjrj.jus.br/web/guest/observatorio-judicial-violenciamulher/projetos/protocolo-violeta-laranja . Acesso em: 30 dez. 2020.

TRIBUNAL DE JUSTIÇA DO ESTADO DO RIO DE JANEIRO. CEJUVIDA. Disponível em http://www.tjrj.jus.br/cejuvida. Acesso em: 30 dez. 2020.

TRIBUNAL DE JUSTIÇA DO ESTADO DO RIO DE JANEIRO. Aplicativo Maria da Penha Virtual. Disponível em http://www.tjrj.jus.br/web/guest/observatorio-judicialviolencia-mulher/aplicativo-maria-da-penha-virtual. Acesso em: $30 \mathrm{dez} .2020$

TRIBUNAL DE JUSTIÇA DO ESTADO DO RIO DE JANEIRO. Campanha 'Confinamento sem Violência': mais um telefone (197) para ajudar vítimas de maustratos. Disponível em http://www.tjrj.jus.br/noticias/noticia/-/visualizarconteudo/5111210/7268064. Acesso em: 30 dez. 2020

TRIBUNAL DE JUSTIÇA DO ESTADO DO RIO DE JANEIRO. Sala Lilás. Disponível em: http://www.tjrj.jus.br/web/guest/observatorio-judicial-violencia-mulher/projetos$\underline{\text { convenios/sala- }}$

lilas\#: :text=A\%20Sala\%20Li1\%C3\%A1s\%20\%C3\%A9\%20um,Instituto\%20M\%C3\% A9dico\%20Legal\%20(IML).\&text=A\%20integra\%C3\%A7\%C3\%A30\%20dos\%20servi \%C3\%A7os\%20pretende,falar\%20sobre\%20a\%20viol\%C3\%AAncia\%20sofrida.

Acesso em: 30 dez. 2020. 